\section{Paradoxical gastrointestinal effects of interleukin-17 blockers}

We read with great interest the review written by Fauny et al ${ }^{1}$ which describes the relevance of interleukin-23/T-helper 17 (IL-23/Th17) pathway in inflammatory bowel disease (IBD). However, drugs targeting IL-17 have shown the opposite effect with worsening of the disease seen in patients with IBD leading to premature termination of various trials. ${ }^{2}{ }^{3}$ Not only that, IL-17 inhibitors have also triggered new onset IBD in patients with spondyloarthritis. Consequently, the authors suggest a careful search for symptoms or family history of IBD as well as screening using faecal calprotectin levels in patients being planned for anti-IL-17 therapy. So far, the exact mechanism of this perplexing effect has not been elucidated and the authors have suggested that decreased intestinal barrier, predisposition to infection and subsequent inflammation may be responsible for worsening of IBD following anti-IL-17 therapy. We hereby describe other plausible pathways that can explain the same.

Th17 cells were first described in $2005^{4}$ by Langrish et al in a mice model of experimental autoimmune encephalitis. Since then, their role has been described in various autoimmune diseases including rheumatoid arthritis (RA), psoriatic arthritis (PsA), ankylosing spondylitis (AS) and IBD. ${ }^{5}$ Therapies targeting the same have been beneficial in patients with AS and PsA leading to their use as second-line therapies after TNF (tumour necrosis factor) inhibitors. ${ }^{6}$ However, trials using drugs targeting IL-17 have failed or at best been modestly effective in RA and uveitis, ${ }^{78}$ and have been detrimental in IBD. ${ }^{1}$

An interesting concept that has recently evolved explains lack of efficacy of blocking IL-17 in a murine model of experimental autoimmune uveitis. ${ }^{9}$ In an elegant series of experiments, the authors propose an autocrine loop in which IL-17A by acting through NF-kB, induces IL-24 production by Th17 cells. IL-24 then acts as a regulatory cytokine and represses IL-17F and granulocyte macrophage colony stimulating factor (GM-CSF) through SOCS1 and SOCS3. IL-24 is a member of IL-10 family of cytokines which signals through the IL-20 receptor. ${ }^{10}$ The receptors for IL-24 are mainly expressed on epithelial cells including the colonic mucosa. It is produced by activated immune cells including $\mathrm{T}$ and $\mathrm{B}$ cells, and has a suppressor effect on Th1 and Th17 cells. ${ }^{11}$ In Th17 cells, IL-24 transcription occurs in late phase of activation suggesting that it may have a role in regulation of Th17 response. High levels of IL-24 have been demonstrated in the skin in psoriasis, synovial fluid in RA and intestinal mucosa in IBD; however, it seems to have an immune regulatory role. ${ }^{12}$ The recent paper actually proves that induction of IL-24 in turn inhibits IL-17F and GM-CSF production. ${ }^{9}$

Further, IL-24 increases mucin production by increasing MUC gene expression supporting suppressive effects on mucosal inflammation in IBD. ${ }^{13}$ A dose-dependent action of IL-24 has been seen, with lower doses suppressing the Th1 cells and higher doses promoting Th1 and Th17 mediated inflammation. ${ }^{14}$ Thus, blocking IL-17A might interfere with this regulatory loop and lead to worsening of inflammation. This needs to be further evaluated in animal models of IBD as it may imply that dual IL-17A and F blockade with drugs (bimekizumab) could be effective in IBD.

Further, patients with IBD who had evidence of higher inflammatory load like elevated C-reactive protein and faecal calprotectin showed a poor response to secukinumab. ${ }^{2}$ The same trial also demonstrated absence of the minor allele of TNF-like ligand 1A (TL 1A) to be strongly associated with lack of response. TL
1A, expressed by macrophages, along with IL-23, promotes interferon gamma and IL-17 production by $\mathrm{T}$ cells in the gut mucosa. ${ }^{15}$ In a dextran sodium sulphate mice model of IBD, overexpression of TL $1 \mathrm{~A}$, probably by reducing barrier proteins like occludin and claudin-1 through Th9 cells, increased gut permeability resulting in subsequent inflammation. ${ }^{16}$

Thus, though the exact reason for the paradox of IL-17 inhibition in IBD is not known, but interference in the gut mucosal barrier, a possible regulatory role of IL-17A via IL-24, excessive inflammation mediated by TL $1 \mathrm{~A}$ and underlying genetic basis may explain this puzzle partly. Understanding this paradox can throw light on complex role of IL-17 in autoimmune diseases and chronic inflammation.

\section{Pankti Mehta $\odot$, Able Lawrence, Amita Aggarwal}

Department of Clinical Immunology and Rheumatology, Sanjay Gandhi Postgraduate Institute of Medical Sciences, Lucknow, UP, India

Correspondence to Professor Amita Aggarwal, Clinical Immunology, Sanjay Gandhi Post Graduate Institute of Medical Sciences, Lucknow, UP 226014, India; aa.amita@gmail.com

\section{Twitter Pankti Mehta @PanktiMehta24}

Contributors PM was involved in the ideation and writing of the draft. AL and AA were involved in intellectual review and editing. All authors agreed on the final draft.

Funding The authors have not declared a specific grant for this research from any funding agency in the public, commercial or not-for-profit sectors.

Competing interests None declared.

Patient and public involvement Patients and/or the public were not involved in the design, or conduct, or reporting, or dissemination plans of this research.

Patient consent for publication Not required.

Provenance and peer review Not commissioned; internally peer reviewed.

(c) Author(s) (or their employer(s)) 2020. No commercial re-use. See rights and permissions. Published by BMJ.

\section{Check for updates}

To cite Mehta P, Lawrence A, Aggarwal A. Ann Rheum Dis Epub ahead of print: [please include Day Month Year]. doi:10.1136/annrheumdis-2020-218719

Received 29 July 2020

Accepted 2 August 2020

Ann Rheum Dis 2020:0:1-2. doi:10.1136/annrheumdis-2020-218719

\section{ORCID iD}

Pankti Mehta http://orcid.org/0000-0001-9134-0999

\section{REFERENCES}

1 Fauny M, Moulin D, D'Amico F, et al. Paradoxical gastrointestinal effects of interleukin-17 blockers. Ann Rheum Dis 2020. doi:10.1136/ annrheumdis-2020-217927. [Epub ahead of print: 21 Jul 2020].

2 Hueber W, Sands BE, Lewitzky S, et al. Secukinumab, a human anti-IL-17A monoclonal antibody, for moderate to severe Crohn's disease: unexpected results of a randomised, double-blind placebo-controlled trial. Gut 2012;61:1693-700.

3 Targan SR, Feagan B, Vermeire S, et al. A randomized, double-blind, placebocontrolled phase 2 study of Brodalumab in patients with moderate-to-severe Crohn's disease. Am J Gastroenterol 2016;111:1599-607.

4 Langrish $\mathrm{CL}$, Chen Y, Blumenschein WM, et al. IL-23 drives a pathogenic T cell population that induces autoimmune inflammation. J Exp Med 2005:201:233-40.

5 Ruiz de Morales JMG, Puig L, Daudén E, et al. Critical role of interleukin (IL)-17 in inflammatory and immune disorders: An updated review of the evidence focusing in controversies. Autoimmun Rev 2020;19:102429.

6 van der Heijde D, Ramiro S, Landewé R, et al. 2016 update of the ASAS-EULAR management recommendations for axial spondyloarthritis. Ann Rheum Dis 2017;76:978-91.

7 Blanco FJ, Möricke R, Dokoupilova E, et al. Secukinumab in active rheumatoid arthritis: a phase III randomized, double-blind, active Comparator- and placebo-controlled study. Arthritis Rheumatol 2017:69:1144-53.

8 Dick AD, Tugal-Tutkun I, Foster $S$, et al. Secukinumab in the treatment of noninfectious uveitis: results of three randomized, controlled clinical trials. Ophthalmology 2013;120:777-87. 
9 Chong WP, Mattapallil MJ, Raychaudhuri K, et al. The cytokine IL-17A limits Th17 pathogenicity via a negative feedback loop driven by autocrine induction of IL-24. Immunity 2020.

10 Chen J, Caspi RR, Chong WP. IL-20 receptor cytokines in autoimmune diseases. J Leukoc Biol 2018;104:953-9.

11 Anuradha R, Munisankar S, Dolla C, et al. Modulation of CD4+ and CD8+ T-cell function by interleukin 19 and interleukin 24 during filarial infections. J Infect Dis 2016:213:811-5.

12 Persaud L, De Jesus D, Brannigan O, et al. Mechanism of action and applications of interleukin 24 in immunotherapy. Int J Mol Sci 2016;17. doi:10.3390/ijms17060869. [Epub ahead of print: 02 Jun 2016].
13 Andoh A, Shioya M, Nishida A, et al. Expression of IL-24, an activator of the JAK1/ STAT3/SOCS3 cascade, is enhanced in inflammatory bowel disease. J Immunol 2009;183:687-95.

14 Zhang Y, Liu Y, Xu Y. Interleukin-24 regulates T cell activity in patients with colorectal adenocarcinoma. Front Oncol 2019;9:1401.

15 Kamada N, Hisamatsu T, Honda H, et al. TL1A produced by lamina propria macrophages induces Th1 and Th17 immune responses in cooperation with IL-23 in patients with Crohn's disease. Inflamm Bowel Dis 2010;16:568-75.

16 Zhao C, Wang D, Wu M, et al. Tumor necrosis factor ligand-related molecule $1 \mathrm{~A}$ affects the intestinal mucosal barrier function by promoting Th9/interleukin- 9 expression $J$ Int Med Res 2020;48:030006052092601. 